\title{
POPULAÇÃO E ESTRUTURAÇÃO URBANA NO (NOR)OESTE PAULISTA um estudo sobre a produção social do espaço urbano no município de Votuporanga
}

Fabíola Rodrigues

\begin{abstract}
Resumo: Esse artigo tem por objetivo lançar luz sobre os processos demográficos e socioeconômicos recentes (entre 1970 e 2000) decorridos em município paulistas de porte médio, especialmente a reversão da tendência de perdas populacionais e a crescente mobilidade espacial intra-urbana, decorrentes da incorporação desses municípios às novas formas da acumulação flexível, vis-à-vis à precarização do emprego e o crescente empobrecimento da população trabalhadora.

Palavras-chave: População. Desenvolvimento urbano. Mobilidade espacial da população.

Abstract: This article has the objective of throwing some light onto the recent demographic and socioeconomic
processes (between 1970 and 2000) that occurred in most of the municipalities in the State of São Paulo,
especially the reversion of the trend toward demographic losses and the growing intra-urban spatial mobility
resulting from the inclusion of these municipalities into new forms of flexible accumulation, vis-à-vis the
growing unemployment and the increasing impoverishment of the working population.
Key words: Population. Urban development. Spatial mobility of the population.
\end{abstract}

$\mathrm{O}$ objetivo desse artigo é resgatar - de forma geral e aproximada - as condições históricas (decorridas no período entre 1970 e 2000) sob as quais se deu a formação capitalista dos municípios da franja do noroeste paulista, no interior dos processos mais gerais de urbanização, concentração e desconcentração industrial na malha paulista.

De fato, este artigo propõe-se a evidenciar a inter-relação historicamente urdida entre a mobilidade espacial da população, a industrialização e a produção social do espaço urbano, no intento de demonstrar como as disputas pela apropriação dos recursos e das localizações no espaço intra-urbano estão subsumidas às necessidades de reprodução do capital, bem como ao poder de classe na construção da forma espacial da cidade (HARVEY, 1980). Para tanto, estuda o caso de um típico município médio da malha noroeste do Estado: o município de Votuporanga.
Desse modo, o texto foi organizado de forma a permitir a compreensão da evolução sociodemográfica do noroeste paulista no interior do processo de desconcentração industrial e de reversão da tendência de esvaziamento demográfico da franja pioneira. Nesse sentido, estuda particularmente a Região Administrativa (RA) de São José do Rio Preto, onde se localiza o município de Votuporanga.

Na sequiência, a partir da análise das condições históricas que engendraram a formação urbana dessa área, o enfoque recai sobre o município de Votuporanga e as condições mais gerais de sua industrialização, que parecem ter desempenhado um papel decisivo na forma espacial da cidade, sobretudo ao longo das duas últimas décadas.

Dessa perspectiva, acompanha-se a evolução da industrialização e a conformação das primeiras áreas industriais, vis-à-vis à nova forma espacial que a cidade adquire e consolida, evidenciando-se uma relação permanente (e 
levada ao limite, na década de 2000) entre dinâmica econômica, mobilidade espacial da população e produção social do espaço intra-urbano.

\section{PANORAMA DA DINÂMICA DEMOGRÁFICA DO NOROESTE PAULISTA}

A evolução dos volumes e das taxas de crescimento da população da Região Administrativa de São José do Rio Preto, ${ }^{1}$ entre 1970 e 2000 , é bastante elucidativa do movimento de declínio e posterior recuperação econômica e demográfica do interior de São Paulo, especialmente do Oeste Paulista.

Efetivamente, os grandes processos de industrialização e urbanização ocorridos em larga escala no país entre as décadas de 60/70 (MARTINE, 1987; PACHECO; PATARRA, 1997) e que redundaram na extraordinária concentração demográfica na capital paulista e em sua área de influência mais imediata, causaram grande prejuízo ao crescimento urbano e demográfico dos municípios recémformados na franja pioneira paulista.

Esses municípios também foram bastante afetados pela expansão da fronteira agrícola na direção centro-oeste do país (MARTINE, 1987), de modo que seu crescimento econômico e demográfico declinou sensivelmente no período 1960/70 - tendência que só esboçou reversão para o conjunto de municípios dessa região a partir dos anos 80 .

É bastante emblemático do processo de reversão do esvaziamento demográfico no Oeste Paulista o vigoroso crescimento das Regiões de Governo da RA de São José do Rio Preto, expressos na Tabela 1, que mostra uma significativa evolução da taxa de crescimento da população de todas as áreas no período 1970-2000.

Notamos, em primeiro lugar, uma inequívoca liderança da RG de São José do Rio Preto, seguida pela RG de Catanduva na composição do crescimento populacional da RA, nesse período. Embora as taxas de crescimento das regiões mais novas (Votuporanga, Fernandópolis e Jales) sejam bem mais modestas que as taxas de São José do Rio Preto e Catanduva, é possível perceber uma clara reversão na tendência de crescimento negativo e de evasão populacional. Exemplificando: a RG de Jales, muito afetada na década de 70 pelas políticas de modernização agrícola, passou a reverter sua tendência de perda à medida que paulatinamente foi conseguindo fixar sua população rural em atividades urbanas.

Assim, as modestas taxas de crescimento positivo da população nas RGs de Fernandópolis e Votuporanga nos
TABELA 1

Taxa de Crescimento Geométrico Anual da População Região Administrativa de São José do Rio Preto e Regiões de Governo - 1970-2000

\begin{tabular}{|c|c|c|c|}
\hline \multirow{3}{*}{ Regiões } & \multicolumn{3}{|c|}{ Em porcentagem } \\
\hline & \multicolumn{3}{|c|}{ Taxa de Crescimento } \\
\hline & $1970 / 80$ & $1980 / 1991$ & $1991 / 2000$ \\
\hline $\begin{array}{l}\text { Região Administrativa de } \\
\text { São José do Rio Preto }\end{array}$ & 0,71 & 1,59 & 1,59 \\
\hline $\begin{array}{l}\text { Região de Governo de } \\
\text { São José do Rio Preto }\end{array}$ & 1,85 & 2,52 & 2,33 \\
\hline $\begin{array}{l}\text { Região de Governo de } \\
\text { Catanduva }\end{array}$ & 1,77 & 1,42 & 1,29 \\
\hline $\begin{array}{l}\text { Região de Governo de } \\
\text { Votuporanga }\end{array}$ & $-0,20$ & 0,87 & 0,91 \\
\hline $\begin{array}{l}\text { Região de Governo de } \\
\text { Fernandópolis }\end{array}$ & $-0,43$ & 0,41 & 0,55 \\
\hline $\begin{array}{l}\text { Região de Governo de } \\
\text { Jales }\end{array}$ & $-1,80$ & 0,27 & 0,50 \\
\hline
\end{tabular}

Fonte: IBGE; Fundação Seade (1990-2004).

períodos entre 1980/1991 e 1991/2000 (sempre inferiores a $1 \%$ ao ano) traduzem a paulatina capacidade dessas áreas de reter a população em atividades urbanas regulares - isto, num contexto de capitalização das relações sociais de produção no campo e de fortalecimento de sub-pólos regionais com relativa capacidade de absorção de uma população pouca qualificada e precariamente escolarizada.

\section{Região de Governo de Votuporanga}

De modo geral, tanto a RG de Votuporanga quanto o município-sede apresentaram no período 1970-2000 uma evolução demográfica bastante semelhante à analisada anteriormente para o conjunto da Região Administrativa de São José do Rio Preto.

Isso significa dizer que também aqui ocorreram os processos de reversão da tendência de esvaziamento demográfico, esvaziamento esse, configurado no período 1960/ 70 , bem como o processo de fortalecimento do município-sede.

Sob esse aspecto, a Tabela 2 reitera e evidencia o processo de reversão do esvaziamento demográfico dos municípios da RG de Votuporanga: como se pode observar no período 1991-2000 (que mostra a intensidade do crescimento da população em um momento em que a reversão já está em curso) 9 dos 15 municípios que 
TABELA 2

Taxa de Crescimento Geométrico Anual da População, segundo Municípios Região de Governo de Votuporanga - 1991-2004

Em porcentagem

\begin{tabular}{|c|c|c|}
\hline \multirow{2}{*}{ Municípios } & \multicolumn{2}{|c|}{ Taxa de Crescimento } \\
\hline & $1991-2000$ & $2000-2004$ \\
\hline Álvares Florence & $-1,75$ & $-0,78$ \\
\hline Américo de Campos & $-0,03$ & 0,08 \\
\hline Cardoso & $-0,61$ & 0,00 \\
\hline Cosmorama & $-0,67$ & $-0,24$ \\
\hline Floreal & $-1,04$ & $-0,52$ \\
\hline Macaubal & 0,02 & 0,45 \\
\hline Magda & $-0,79$ & $-0,28$ \\
\hline Monções & $-0,35$ & 0,09 \\
\hline Nhandeara & $-0,18$ & 0,47 \\
\hline Parisi & 2,76 & 2,49 \\
\hline Pontes Gestal & $-1,69$ & 1,72 \\
\hline Riolândia & 1,12 & 0,98 \\
\hline Sebastianópolis do Sul & 0,19 & 0,54 \\
\hline Valentim Gentil & 4,31 & 3,39 \\
\hline Votuporanga & 1,8 & 1,49 \\
\hline
\end{tabular}

Fonte: IBGE; Fundação Seade (2004).

compõem a RG de Votuporanga apresentavam taxas de crescimento negativo, ainda que baixas (à exceção de Álvares Florence e Pontes Gestal, que apresentam altas taxas negativas, os demais municípios apresentavam taxas negativas que se aproximam de zero); já no período 20002004 apenas 4 dos 15 municípios da RG apresentam taxas negativas de crescimento e, ainda assim, elas são significativamente menores em comparação com o período anterior (Álvares Florence passa de uma taxa geométrica de crescimento anual de $-1,75 \%$ para $-0,78 \%$; Pontes Gestal salta de uma taxa geométrica de crescimento anual de $-1,69 \%$ para $1,72 \%$ ).

Cumpre destacar, ainda, as excepcionais taxas de crescimento da população, entre os períodos 1991-2000 e 2000-2004, dos municípios de Parisi (2,76\% ao ano e $2,49 \%$ ao ano, respectivamente) e de Valentim Gentil $(4,31 \%$ ao ano e $3,39 \%$ ao ano, respectivamente) que, a despeito de terem diminuído sua intensidade no último período, em comparação com o período anterior, mantêmse significativamente acima das taxas registradas para o total da RG de Votuporanga $(0,91 \%$ e $1,05 \%$, respectivamente), RA de São José do Rio Preto $(1,59 \%$ e 1,43\%) e Estado de São Paulo (1,82\% e 1,55\%) (FUNDAÇÃO SEADE, 2004).
As taxas geométricas de crescimento da população significativamente mais elevadas para esses dois municípios explicam-se, no entanto, em razão de conjunturas bastante particulares: no caso do município de Parisi, o recente desmembramento (1991) parece ter contribuído para seu insígne desempenho, corroborando uma tendência já exaustivamente analisada na constituição urbana da malha paulista (CAMARGO, 1981); no caso de Valentim Gentil, a explicação repousa, possivelmente, no bom desempenho da economia local, especialmente da indústria moveleira, sobremaneira do segmento de estofados. ${ }^{2}$

No que diz respeito às trocas migratórias do município de Votuporanga, no contexto intra-regional, conforme o demonstra a Tabela 3 , nota-se que praticamente todos os municípios da RG de Votuporanga aumentam sua capacidade de retenção migratória no período 1995-2000, em comparação com o período 1986-1991, uma vez que o município-sede diminui o volume do saldo migratório em suas trocas com quase todos os municípios da RG, aumentando, inclusive, as perdas migratórias que, no período 1986-1991 ocorriam apenas nas trocas com os municípios de Macaubal (-41 pessoas) e Sebastianópolis do Sul (-51 pessoas).

Assim, no período 1995-2000, o saldo migratório negativo ocorre também nas trocas com os municípios de Cosmorama (-6 pessoas), Floreal (-26 pessoas), Monções (-11 pessoas), Pontes Gestal (-111 pessoas), Riolândia (-16 pessoas) e Sebastianópolis do Sul (-6 pessoas).

Esses números apontam, concomitantemente, para dois fenômenos para os quais deve-se atentar: o primeiro é a célere e tardia desruralização da população e da economia dos municípios da RG de Votuporanga, nos últimos 20 anos o que contribui sensivelmente para a retenção de população, que muda sua situação de domicílio (de rural para urbano) muitas vezes dentro do mesmo município, induzindo a uma diminuição do fluxo migratório para Votuporanga.

O segundo fenômeno é a crescente informalização da economia votuporanguense, aliada aos processos de liofilização da estrutura produtiva (ANTUNES, 2003), modernização tecnológica e aumento do desemprego diferencial $^{3}$ (que afeta mais intensamente a mão-de-obra de baixa qualificação) em curso na indústria local, particularmente na indústria moveleira, desde meados da década de 90 o que contribuiu para a diminuição da atratividade migratória do município-sede, haja vista que as transformações recentes no regime de acumulação limitam sensivelmente a capacidade de absorção de mãode-obra do setor produtivo do município. 
TABELA 3

Trocas Migratórias, segundo Municípios

Região de Governo de Votuporanga - 1986-2000

\begin{tabular}{|c|c|c|c|c|c|c|}
\hline \multirow{2}{*}{ Municípios } & \multicolumn{3}{|c|}{ 1986-1991 } & \multicolumn{3}{|c|}{$1995-2000$} \\
\hline & Imigração & Emigração & Saldo Migratório & Imigração & Emigração & Saldo Migratório \\
\hline Total & 1.975 & 1.053 & 922 & 265 & 107 & 158 \\
\hline Álvares Florence & 435 & 76 & 359 & 211 & 67 & 144 \\
\hline Américo de Campos & 234 & 41 & 193 & 158 & 16 & 142 \\
\hline Cardoso & 252 & 135 & 117 & 194 & 95 & 99 \\
\hline Cosmorama & 426 & 317 & 109 & 112 & 118 & -6 \\
\hline Floreal & 73 & 26 & 47 & 0 & 26 & -26 \\
\hline Macaubal & 47 & 88 & -41 & 36 & 7 & 29 \\
\hline Magda & 67 & 0 & 67 & 37 & 14 & 23 \\
\hline Monções & 40 & 0 & 40 & 0 & 11 & -11 \\
\hline Nhandeara & 105 & 87 & 18 & 109 & 73 & 36 \\
\hline Pontes Gestal & 22 & 0 & 22 & 131 & 242 & -111 \\
\hline Riolândia & 73 & 50 & 23 & 23 & 39 & -16 \\
\hline Sebastianópolis do Sul & 0 & 51 & -51 & 125 & 131 & -6 \\
\hline Valentim Gentil & 201 & 182 & 19 & 10 & 0 & 10 \\
\hline
\end{tabular}

Fonte: IBGE. Censo Demográfico 1991 e 2000 (tabulações especiais)

\section{AS (TRANS)FORMAÇÕES DA CIDADE INDUSTRIAL}

\section{A Emergência da Cidade Industrial}

Assim como ocorreu com os fluxos migratórios, a reversão da tendência de esvaziamento demográfico e o crescente fortalecimento do município de Votuporanga como pólo econômico regional configuraram-se como determinantes de primeira grandeza para a formação de uma morfologia urbana específica. O aparecimento das primeiras áreas industriais no final dos anos 70 explica a forma urbana - marcada pela forte segregação residencial - que a cidade adquiriu e consolidou nas décadas seguintes.

Isso equivale dizer, como o demonstra o Mapa 1, que a implantação de distritos industriais no município de Votuporanga desde o final da década de 70 foi deveras determinante para a conformação do desenho urbano e para a orientação da distribuição da população no espaço intra-urbano.

Foi essencialmente a partir da estruturação do Pólo Comercial e Industrial de Votuporanga (1979) e dos dois primeiros distritos industriais (1978 e 1979, respectivamente) que se abriu uma frente de expansão ao norte e noroeste do perímetro urbano, conformando um novo eixo de intenso dinamismo econômico.
Graças aos incentivos e regulamentação do Plano $\mathrm{Mu}-$ nicipal de Amparo e Incentivo Industrial de Votuporanga - Plamivo, ${ }^{4}$ houve importante transferência de empresas já sediadas no município, bem como a instalação de novas empresas nas áreas zoneadas para uso industrial, todas localizadas nas franjas do perímetro urbano legal, no sentido norte-noroeste, conformando aglomerações de moradia popular - já que a consolidação da indústria de transformação no município, destacadamente a moveleira (SEMPLA, 1995), requeria a proximidade entre as áreas de moradias operárias e a industrial como forma de otimização dos custos de reprodução do capital.

Nesse sentido, a produção social do espaço urbano (GOTTDIENER, 1997) passa a ser fortemente orientada em função das necessidades das novas aglomerações industriais, as quais demandam políticas de infra-estrutura urbana e de transportes que são apenas parcialmente providas pelo Poder Público.

Dessa forma, a dinâmica de expansão imobiliária no espaço intra-urbano foi-se deslocando paulatinamente do eixo centro-sul para o eixo centro-norte, ratificando o centro tradicional (VILLAÇA, 2001). No entanto, continuou deslocando a configuração dos bolsões de pobreza e das áreas de moradia popular para a frente de expansão norte, gerando um efeito indireto de enobrecimento da zona sul. Tudo isso ocorreu a despeito da permanência de antigos 


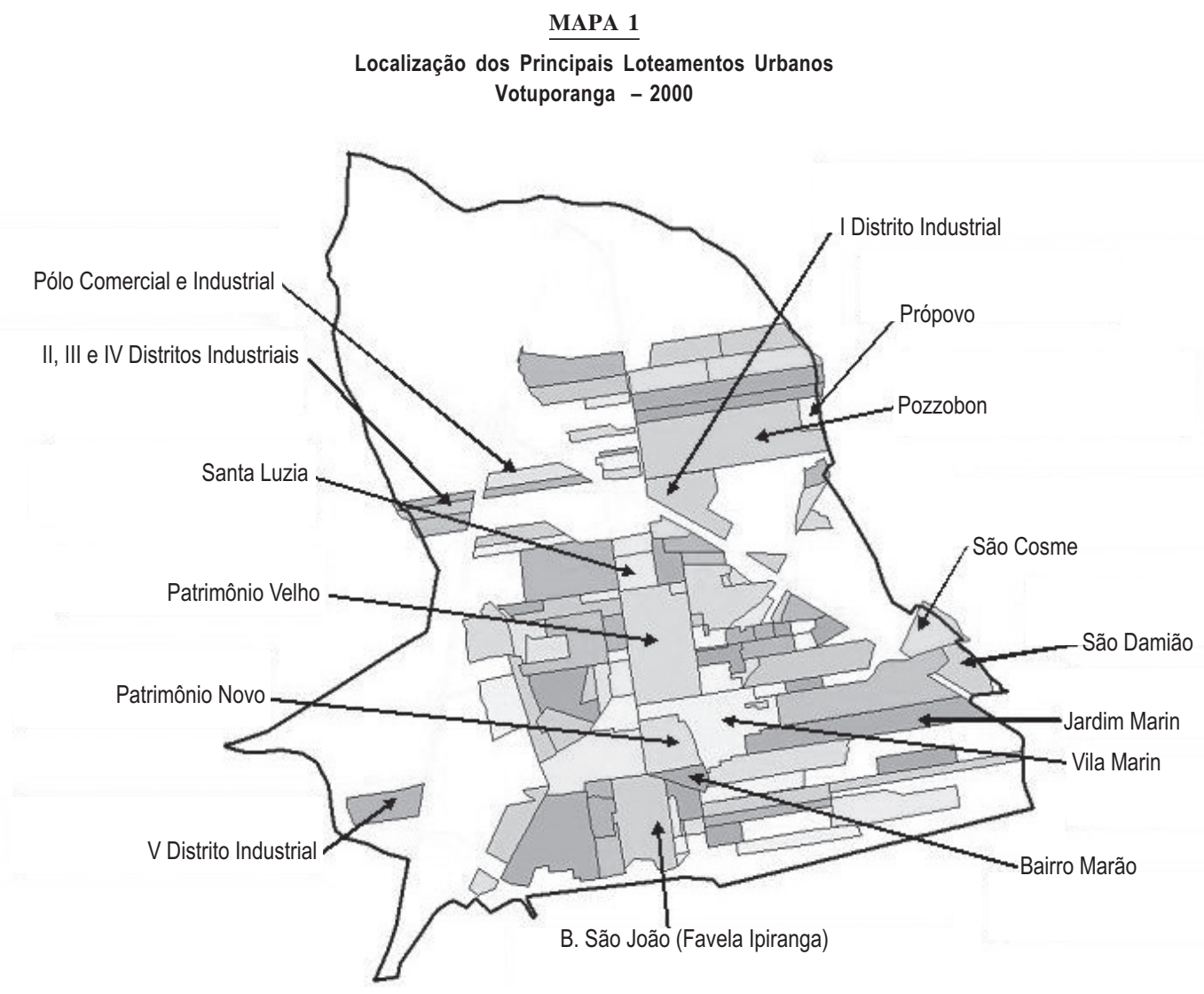

Fonte: Secretaria Municipal de Planejamento, Habitação e Meio Ambiente da Prefeitura Municipal de Votuporanga.

bolsões de pobreza nessa região (como a favela Ipiranga, a mais importante e mais antiga do município), ao longo das décadas seguintes.

Evidentemente, a conformação de aglomerações de moradias populares na frente de expansão norte, além de configurar-se como conveniente para o capital industrial, revelou-se oportuna para o capital imobiliário, que não tardou a plantar inúmeros loteamentos populares naquela região.

O capital imobiliário se beneficiou, ainda, da dinamização do mercado imobiliário suscitada pela ampliação do perímetro urbano efetivamente ocupado, em virtude do adensamento progressivo da zona norte, que gerou, ainda, um rearranjo na apropriação dos recursos físicos do espaço intra-urbano, abrindo novos flancos para uma ocupação das camadas médias na malha consolidada da zona centro-sul.

Efetivamente, a zona de expansão norte ${ }^{5}$ replicou ampliadamente a tensão centro-periferia presente na estruturação urbana ocorrida entre as décadas de 40 e 70, quando a formação de uma pequena economia de aglo- meração na região do Patrimônio Velho (correspondente ao centro histórico) polarizou crescentemente as atividades mais dinâmicas e atraiu as camadas de alta renda para seu entorno, relegando paulatinamente a região da Estação Ferroviária (núcleo econômico e residencial primevo) a funções urbanas mais secundárias.

À medida que a ferrovia foi perdendo importância frente ao transporte rodoviário, as atividades comerciais e industriais ali existentes tenderam a transferir-se, primeiramente, para a área do centro tradicional e, posteriormente, (especialmente no caso das indústrias) para a área dos distritos industriais. Assim, as moradias populares foram subsistindo sobremaneira na região da Estação Ferroviária, conformando essa região (no extremo sul da malha urbana) como zona de periferia urbana.

No final da década de 70, com a estruturação do Pólo Comercial e Industrial de Votuporanga e dos dois primeiros distritos industriais, a especialização urbana das áreas de moradia popular espraiou-se para a zona de expansão norte, ratificando, da perspectiva da produção social do 
espaço, uma dinâmica de apropriação e uso do solo urbano nitidamente marcada pela tensão centro-periferia.

Destarte, embora a periferia urbana tenha se ampliado, mantendo sua conformação no extremo sul do perímetro urbano (cuja funcionalidade justifica-se na medida em que a zona de expansão norte produz a valorização da área centro-sul, cujo enobrecimento demanda crescentemente a proximidade de mão-de-obra de serviços gerais) e avançando sobre a zona de expansão norte, a centralidade do centro tradicional (que pouco avançou nas últimas quatro décadas para fora da área do centro histórico $)^{6}$ mantevese inalterada.

Essa leitura é amplamente endossada pela análise da evolução da abertura de loteamentos no espaço intra-urbano de Votuporanga, desde os primórdios de sua formação urbana, onde se nota, claramente, o aumento no número de loteamentos (mormente voltados para as camadas populares) abertos na década de 80 , especialmente na zona de expansão norte.

Nesse contexto, a partir do centro tradicional, a área da cidade que recebeu os maiores investimentos imobiliários entre as décadas de 50 e 60 foi a porção oeste, donde destacamos os loteamentos Vila América (1956), Loteamento Albino Zan (1961), Loteamento Santa Elisa (1959), Chácara da Aviação (1959), Recanto dos Esportes (1959), Jardim Santo Antônio (1965), Vila Guerche (1966), Chácara das Paineiras (1966), Jardim Paraíso (1967), entre outros.

Conformando uma expansão radial, em direção ao sul do perímetro urbano, foram abertos inúmeros loteamentos na porção mais meridional do município, primeiramente no entorno do bairro da Estação (1950), alongando-se no sentido leste-oeste, donde destacamos: Bairro São João (1952), Parque Guarani (1966), Jardim Umuarama (1967), Chácara Vera (1967), Cecap I (1968), Parque Roselândia (1968), Jardim Progresso (1974), Jardim Santos Dumont (1978), e outros.

Finalmente, a zona de expansão norte configura-se, entre o fim dos anos 70 e o curso da década de 80 , a partir da abertura dos primeiros parques industriais (1978/79), carreando um sem-número de loteamentos populares que adensam e ampliam o perímetro urbano efetivamente ocupado na franja norte: Bairro Pozzobon (1978), Loteamento São Vicente de Paulo (1978), Parque Rio Vermelho (1979), Cohab (1981), Parque Residencial Santa Amélia (1983), Própovo (1988), Parque das Nações I e II (1988), entre outros.

Essa ocupação marcadamente radial do perímetro urbano, primeiro no sentido centro-sul, com expansões a leste e a oeste, e posteriormente, na década de 80 , no sentido centro-norte deixa bastante perceptível a importância econômica, social e política do centro tradicional (do qual as camadas de alta renda não abrem mão), e mais do que isso, evidencia a relação funcional que o centro tradicional estabelece com as periferias urbanas, deixando entrever o poder de classe na estruturação urbana, à medida que os pobres vão sendo reiteradamente expulsos para territórios do espaço intra-urbano mais convenientes à lógica de reprodução do capital. ${ }^{7}$

De fato, a ampliação da mancha urbana na direção norte do perímetro urbano, pulverizando nas franjas da malha as localizações das moradias populares, fez-se concomitantemente a um movimento de adensamento construtivo e demográfico do centro tradicional, que se torna mais complexo e se valoriza frente aos novos investimentos dos capitais industrial e imobiliário.

Assim, a distensão do processo de periferização na direção da malha norte produziu, concomitantemente, maior adensamento, verticalização e intensificação da valorização imobiliária da região central, ao longo das décadas de 80 e 90, vedando-a em definitivo aos pobres e conformando-a como locus do domínio das camadas de alta renda.

O processo de verticalização do centro foi bastante intenso entre as décadas de 80 e 90, de modo que a própria paisagem da região central foi rapidamente alterada, na mesma medida em que sua centralidade econômica, social e política foi fortalecida pela rápida evolução da indústria e pela dinamização do comércio e serviços locais, que expandem sua polarização regional (SEMPLA, 1995).

Em Votuporanga, a clássica tensão centro-periferia é ampliada, na década de 80, a partir da constituição da zona de expansão norte, conformando um modelo de produção social do espaço urbano marcado pela crescente centralidade do centro tradicional e pela distensão da periferia urbana.

Destarte, se por um lado, tem-se em Votuporanga um centro principal classicamente segregado (concentrando crescentemente maiores parcelas das camadas de alta renda, ao longo dos anos 80 e 90, especialmente nos condomínios residenciais verticais), de outro lado, tem-se uma periferia fortemente espraiada (que se amplia de sua localização mais antiga, no extremo sul, na direção do extensor norte), distribuída em diversas aglomerações ao longo das fímbrias do perímetro urbano.

De qualquer modo, a progressiva distensão radial da periferia urbana na direção do extensor norte, aliada à 
necessidade de produção de novas localizações industriais, bem como a expansão concomitante do centro tradicional, configuraram-se como forças determinantes na estruturação do espaço intra-urbano de Votuporanga, entre as décadas de 80 e 90.

Nesse sentido, ainda, a desfuncionalização do I Distrito Industrial (assediado pela crescente proximidade com o centro expandido), bem como as inúmeras transformações no regime de acumulação da indústria votuporanguense (destacadamente a moveleira), mormente a partir de meados da década de 90, estabelecem novas injunções no desenho urbano, alterando rapidamente a paisagem urbana, (re)criando lugares de valor e lugares marginais na contínua produção da cidade do trabalho e da vida cotidiana.

\section{A Velha Dualidade Centro-Periferia: Mobilidade Socioespacial e Pobreza}

A década de 90 marca um momento determinante de modernização e ampliação de abrangência para a indústria moveleira de Votuporanga: influenciada fortemente pela ascendência do Sebrae sobre o Poder Público Municipal local e a entidade representativa regional dos industriais (Associação Industrial da Região de Votuporanga Airvo), inicia-se em 1994 um vigoroso programa ${ }^{8}$ de modernização tecnológica e reestruturação organizacional da indústria moveleira local, até então expressiva em número de fabricantes, mas relativamente obsoleta e com pífia participação no mercado nacional de móveis (RODRIGUES, 2005).

Nesse sentido, a implantação do pólo de modernização da indústria moveleira configura-se como marco da célere modernização da indústria votuporanguense - o que gerou significativos impactos nos níveis de incorporação tecnológica, no volume da produção e na amplitude dos mercados alcançados pela indústria moveleira local.

Por outro lado, quando a indústria moveleira "hibridiza" seus processos produtivos, introduzindo inovações técnicas capazes de substituir o trabalho humano - sobretudo aquele mais braçal, de menor qualificação - essa adequação às novas exigências de qualidade e produtividade obsoletizam uma mão-de-obra particularmente sensível a essas transformações - ou seja, a dos trabalhadores de baixa qualificação, cujas chances de reinserção no mercado de trabalho formal vão diminuindo cada vez mais.

Na verdade, todo o sucateamento da força de trabalho da população de baixa qualificação traduz-se em desesta- bilização das condições de reprodução física e social das camadas populares, cujo empobrecimento (decorrente da precarização do emprego) os obriga a buscar cada vez mais longe as alternativas possíveis de sobrevivência na cidade.

O contínuo deslocamento dos pobres, impulsionado pelas constantes pressões do capital imobiliário, vai esvaziando os loci já constituídos de moradia popular que, valorizados (na medida em que avançam os serviços e se distanciam os pobres), são crescentemente assediados pelas camadas médias.

No município de Votuporanga, essa conjunção entre modernização tecnológica da indústria, achatamento dos salários e precarização das condições de vida da população trabalhadora é reforçada por um padrão de estruturação urbana assumido com a configuração dos primeiros distritos industriais, no final dos anos 70, que nitidamente disjunge a cidade a partir de uma tensão capital/trabalho, que conforma um centro no singular, e periferias, no plural.

Isso significa dizer que o desenho urbano de Votuporanga vem sendo orientado, desde os anos 80 até o presente, especialmente pela lógica de reprodução do capital industrial: o grande vazio urbano da área norte do município foi sendo ocupado, desde o final dos anos 70, pela população operária, de modo a se constituir, naquela porção da cidade, uma importante aglomeração residencial das camadas populares.

Com o adensamento da malha nas décadas seguintes, e com a expansão física do centro tradicional (VILLAÇA, 2001) na direção do extensor norte houve uma paulatina valorização imobiliária das áreas mais próximas do centro expandido, delineando uma discreta alteração no perfil socioeconômico dos moradores da área - especialmente daqueles dos bairros mais antigos, que contavam com uma infra-estrutura urbana de melhor qualidade.

Essa valorização das áreas residenciais localizadas entre as franjas do centro expandido e o entorno do I Distrito Industrial operou uma intensa mobilidade populacional no espaço intra-urbano, com notável expulsão dos mais pobres para loteamentos mais distantes, em localizações menos privilegiadas - e, não raro, em espaços clandestinos de moradia.

Efetivamente, como demonstra o Mapa 2, a malha centro-sul é a mais antiga e já está consolidada, além de dispor de melhor infra-estrutura urbana, expressa pelo maior número de loteamentos. Apesar disso, as maiores densidades demográficas, especialmente dos mais pobres, estavam localizadas, em 2000, na zona de expansão norte. Com sua constituição mais recente e contando com infra- 
estrutura, equipamentos e serviços urbanos disponíveis em menor quantidade, ainda assim, de forma muito assistemática, essa área abrangia, basicamente, os bairros mais próximos ao I Distrito Industrial - cuja valorização tem atraído crescentes parcelas das camadas médias.

Assim, na espacialização da população de Votuporanga em 2000, pode-se enxergar uma nítida disjunção entre as localizações centrais do capital e as localizações periféricas das camadas populares (no extremo sul e na zona de expansão, no extremo norte) - o que reflete a existência de disputas de classe pelo domínio do espaço intra-urbano.

Nesse contexto, o nítido crescimento das favelas em Votuporanga, ${ }^{9}$ especialmente na década de 2000, sinaliza muito claramente a diminuição da qualidade de vida da população trabalhadora, resultado, em certa medida, do processo de reestruturação produtiva que alterou sen- sivelmente a estrutura organizacional e ocupacional da indústria de transformação, destacadamente a da moveleira, outrora com grande capacidade de absorção de mão-deobra, especialmente aquela de baixa qualificação.

As transformações recentes na estrutura produtiva da indústria, com o conseqüente enxugamento organizacional e redução das plantas produtivas redundou em aumento do desemprego e depreciação da renda do trabalhador.

Desse modo, a capacidade de pagamento da habitação, pelas camadas operárias, reduziu-se, significativamente, o que redundou, para muitas famílias, na busca de outras soluções habitacionais possíveis (inclusive a favela) ou no deslocamento para áreas em que o custo da habitação fosse compatível com o poder aquisitivo dessas famílias.

De fato, nesse contexto de precarização das condições de vida das camadas populares, houve uma intensificação dos deslocamentos intra-urbanos, fruto da necessidade de

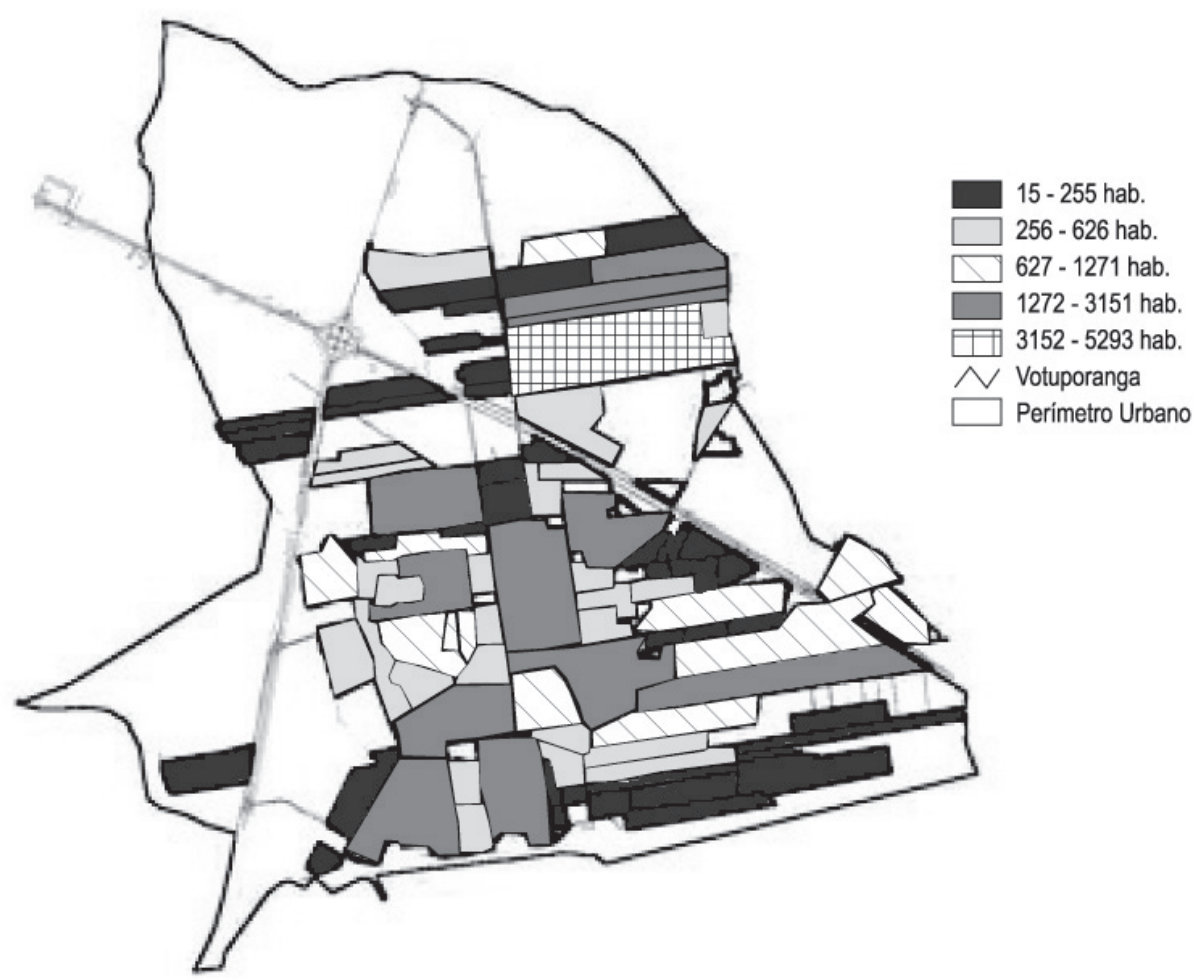

Fonte: Secretaria Municipal de Planejamento, Habitação e Meio Ambiente da Prefeitura Municipal de Votuporanga. 
reequacionar o orçamento familiar com os custos da habitação.

Efetivamente, a multiplicidade de deslocamentos intraurbanos identificados dentre a população das camadas mais empobrecidas $^{10}$ é bastante reveladora da inacessibilidade da cidade a essa população que, a despeito de engendrar sua riqueza, não pode dela se apropriar, estando permanentemente empurrada para a margem - do espaço, do consumo e da cidadania.

Isso significa dizer que a trajetória residencial da empobrecida classe trabalhadora, marcada por múltiplos e sucessivos deslocamentos, permite-nos enxergar como a produção social do espaço urbano é perpassada pela luta de classes e, mais do que isso, como o espaço, enquanto produto do trabalho social (RODRIGUES, 1994), é apropriado diferencialmente pelas distintas camadas sociais, revelando que, a despeito de despenderem esforços para sua produção, os pobres usufruem parcelas muito diminutas (e no mais das vezes desprestigiadas) do espaço socialmente produzido.

A Tabela 4 nos permite, ainda, visualizar a enorme concentração de renda no município de Votuporanga, exatamente da perspectiva da localização espacial das classes sociais: assim, enquanto no Patrimônio Velho (loteamento incrustado no core do centro tradicional), os chefes de domicílio percebem uma renda média mensal de R\$ 6.504,01, na Favela PróPovo (incrustada na zona de expansão norte), os chefes percebem uma renda média mensal de $\mathrm{R} \$ 127,82$. Ou seja: a diferença de renda que separa os chefes do Patrimônio Velho dos chefes do PróPovo é da ordem de 50,82 vezes.

Deve-se observar, ainda, que todos os cinco loteamentos que concentram a população de maior renda em Votuporanga, estão localizados na zona central da cidade, enquanto a população mais pobre acha-se espraiada em loteamentos nos pontos mais distantes e de pior acessibilidade no espaço intra-urbano.

Efetivamente, em Votuporanga, a enorme concentração de renda aliada às crescentes dificuldades de inserção dos trabalhadores no mercado formal de trabalho - com a conseqüente precarização das condições de vida das famílias operárias - vai pouco a pouco transformando a cidade no não lugar para significativas parcelas da população que apresentam notáveis dificuldades em fixarse no espaço urbano e até mesmo garantir as condições necessárias para sua reprodução física e social.

De fato, as recentes transformações em curso na economia votuporanguense (especialmente a reestruturação
TABELA 4

Renda Média Nominal Mensal do Chefe de Domicílio, segundo Principais Áreas de Loteamentos Urbanos Votuporanga - 2000

\begin{tabular}{lcc}
\hline Áreas de Loteamento & $\begin{array}{c}\text { Renda Média } \\
(\mathrm{R} \$)\end{array}$ & $\begin{array}{c}\text { Localização } \\
\text { do Loteamento }\end{array}$ \\
\hline Votuporanga (Total) & 807,2 & - \\
Favela Própovo & 127,82 & Norte \\
Patrimônio Velho & $6.501,04$ & Centro \\
Jardim Santos Dumont & 211,57 & Sudoeste \\
São Cosme & 254,43 & Leste \\
São Damião & 234,04 & Leste \\
Santa Luzia & 1212,9 & Centro \\
Patrimônio Novo & $3.730,68$ & Centro \\
Jardim Marin & $1.235,22$ & Centro-Leste \\
Vila Marin & 4504,3 & Centro \\
Favela Ipiranga & 215,31 & Sul \\
\hline
\end{tabular}

Fonte: Prefeitura Municipal de Votuporanga. Sistema de Informações Georreferenciadas (SIG): IBGE. Censo Demográfico 2000 (Setores censitários).

produtiva do setor moveleiro) aliadas a um déficit habitacional histórico ${ }^{11}$ - produto de relações desabonadoras entre o Poder Público e o capital imobiliário intensificaram nos primeiros anos da década de 2000 um padrão de produção social do espaço marcado por inúmeras desigualdades na apropriação e uso dos recursos físicos e simbólicos do espaço urbano.

Destarte, esse contexto local de acelerada obsoletização da força de trabalho, concomitante com a interinidade da localização residencial das famílias mais empobrecidas, permite-nos algumas comparações com os grandes processos em curso de periferização, empobrecimento e precarização das condições de vida da população nas grandes aglomerações urbanas brasileiras.

De fato, a análise dos deslocamentos populacionais intra-urbanos em Votuporanga na sua relação com a estruturação urbana pontuou que a segregação socioespacial, a extrema concentração de renda (que se reflete na capacidade diferencial de apropriação do espaço) e a periferização das camadas populares não são privilégios das metrópoles, na rede urbana brasileira. Esses processos também ocorrem - de formas diferenciadas e com intensidades e nuances particulares - em cidades médias, de constituição recente, mas onde, igualmente, os interesses do capital privado sobrepõe-se permanentemente aos interesses coletivos, comprometendo significativamente o acesso universal à cidade. 


\section{CONSIDERAÇÕES FINAIS}

A problemática dos deslocamentos populacionais intraurbanos parece ter sido tratada de forma pouco atenciosa pelos estudiosos de migração. Entretanto, a relevância demográfica dos deslocamentos intra-urbanos (que tende a ser negligenciada em um contexto de crescente facilitação das comunicações e encurtamento das distâncias pela maior disponibilidade e barateamento dos transportes) reside na sua força enquanto fenômeno social: quando as pessoas se deslocam no espaço intra-urbano, seu movimento não é um riscado sem ordem; o mapeamento e a espacialização dos fluxos e deslocamentos populacionais permite enxergar, nitidamente, mesmo no urbano pequeno, que são as classes sociais que estruturam o espaço.

Mas afinal de contas, por que nos importa a afinidade eletiva dos deslocamentos intra-urbanos e a estruturação do espaço? A resposta a essa questão é complexa e não se esgota em um estudo de caso - que, de forma geral, procurou evidenciar a emergência de um perverso padrão de estruturação urbana, a partir da sua relação com a mobilidade intra-urbana da população e o seu crescente empobrecimento, decorrente das inúmeras transformações nos níveis de emprego da indústria local, revelando que a periferização das camadas populares e a segregação sócio-espacial das camadas de alta renda também são processos presentes nas pequenas e médias cidades paulistas.

Na verdade, o desafio que nos é lançado pela questão da afinidade eletiva entre os deslocamentos intra-urbanos e a estruturação urbana é a renitente problemática relativa às razões pelas quais as pessoas migram. E a resposta tão pungente, que parece emergir dos estudos de migração - abranjam estes longas distâncias, curtas distâncias ou pequeníssimas distâncias intra-urbanas - é que todos parecem revelar o profundo paradoxo entre a crescente urbanização da população paulista e brasileira e o forte recrudescimento, em tempos de globalização, da espoliação urbana. E é essa espoliação que torna as cidades meras abstrações simbólicas, nas quais o pertencimento, a sociabilidade e os laços de solidariedade, apoio e afinidade são apenas um brevíssimo vislumbre, num universo em que não existem utopias e a itinerância é uma condenação.

\section{NOTAS}

1. A Região Administrativa (RA) de São José do Rio Preto, que engloba o município de Votuporanga, compõe-se de 81 municípios, consti- tuindo-se uma das áreas mais importantes (ao lado da RA de Araçatuba) da porção norte-ocidental da malha paulista.

2. Essa hipótese baseia-se na análise dos dados da Relação Anual de Informações Sociais - Rais de 2001/2002 relativos à indústria moveleira de Votuporanga e Valentim Gentil.

3. A respeito da temática da reestruturação produtiva no Brasil na década de 90, veja-se especialmente: Ferreira (1997) e Suzigan (2004), dentre outros.

4. O Plamivo, sancionado pelo prefeito Hernani de Mattos Nabuco, em 1970, constituía-se basicamente em um plano de incentivos fiscais com vistas a subsidiar a industrialização de Votuporanga. As diretrizes e incentivos do Plamivo foram determinantes para a conformação dos primeiros distritos industriais em Votuporanga, bem como para a conformação do tecido urbano nas décadas subseqüentes.

5. A zona de expansão norte refere-se à área surgida no entorno do Pólo Comercial e Industrial (1979), I Distrito Industrial (1978) e do Loteamento Residencial Pozzobon (1978) (ver Mapa 1).

6. Sobre a relação entre classes sociais e estruturação urbana veja-se, dentre outros, Lefebvre (1974), Kowarick, (1983); Santos (1979; 1996; 2000) e Villaça (2001).

7 A distinção entre centro tradicional e centro histórico é postulada por Villaça (2001): na concepção do autor o que define uma centralidade é a sua capacidade de otimizar os custos de deslocamento e maximizar as condições de acessibilidade; assim, o centro tradicional é aquele que dentro da malha urbana representa o ponto que permite a máxima acessibilidade e a maior economia de tempo de deslocamento no espaço intra-urbano, em um dado momento no tempo. Já o centro histórico diz respeito à área de constituição mais remota que no espaço intraurbano assumiu o papel de centro tradicional. Desse modo, o centro histórico pode ou não coincidir com o centro tradicional recente de uma cidade, dependendo das características históricas de sua evolução urbana.

8. Refere-se ao projeto de Pólos de Modernização do Estado de São Paulo, fruto de uma pareceria Sebrae/FIA-USP (FERREIRA, 1997; SUZIGAN, 2004).

9. A taxa geométrica de crescimento das favelas de Votuporanga, entre 1996 e 2001, foi de $6,58 \%$ ao ano (calculado a partir dos dados da Secretaria Municipal de Planejamento - Sempla, 2002) enquanto a taxa geométrica de crescimento da população do município entre 1991-2000 foi de $1,8 \%$ ao ano (FUNDAÇÃO SEADE, 2004)

10. Para a dissertação de mestrado (RODRIGUES, 2005) da qual esse artigo é produto, foram entrevistadas 20 pessoas, dentre trabalhadores e ex-trabalhadores da indústria moveleira, residentes em favelas ou bolsões de pobreza. Das entrevistas foi possível constatar que, em média, os trabalhadores residentes em loteamentos regulares haviam realizado, até o momento da pesquisa, em torno de dois deslocamentos residenciais no município, enquanto aqueles residentes em favelas haviam realizado, em média, quatro deslocamentos, o que parece confirmar a maior instabilidade da habitação para a população mais empobrecida.

11. De acordo com informações da Sempla, de Votuporanga, o déficit habitacional, em 2004, era de aproximadamente 2.500 unidades habitacionais, abrangendo cerca de $10 \%$ da população do município (cf. RODRIGUES, 2005, especialmente cap. 3).

\section{REFERÊNCIAS BIBLIOGRÁFICAS}

ANTUNES, R. Os caminhos da liofilização organizacional: as formas diferenciadas da reestruturação produtiva no Brasil. Revista Idéias. Campinas, IFCH/Unicamp, ano 9, n. 2/ ano 10, n. 1, 2002/ 2003. 
CAMARGO, J.F. de. Crescimento da população no Estado de São Paulo e seus aspectos econômicos. São Paulo: IPE/USP, 1981. v. 1.

CANO, W. Raízes da concentração industrial em São Paulo. 2. ed. São Paulo: TA Queiroz, 1977.

FERREIRA, M.J.B. Pólo moveleiro de Votuporanga. Campinas: IE/ Unicamp, 1997. (Relatório de Pesquisa do Projeto Design como fator de competitividade na indústria moveleira).

FUNDAÇÃO SEADE. Informações dos municípios paulistas. São Paulo: 2004. Disponível em: <http://www.seade.gov.br>.

Informe Demográfico n. 23. São Paulo: 1981.

GOTTDIENER, M. A produção social do espaço urbano. São Paulo: Edusp, 1997.

HARVEY, D. A justiça social e a cidade. São Paulo: Hucitec, 1980.

IBGE. Censo Demográfico 1970 a 2000. Rio de Janeiro: vários anos.

KOWARICK, L. A espoliação urbana. Rio de Janeiro: Paz e Terra, 1983.

MARTINE, G. Migração e metropolização. São Paulo em Perspectiva, São Paulo, Fundação Seade, v. 1, n. 2, p. 28-31, jul./set. 1987.

MINISTÉRIO DO TRABALHO E EMPREGO. Relação Anual de Informações Sociais. Brasília, DF: 1996-2002.

PACHECO, C.A.; PATARRA, N.L. Movimentos migratórios nos anos 80: novos padrões? In: ENCONTRO NACIONAL SOBRE MIGRAÇÃO. Anais.... Curitiba: 1997.
PAVAM, J.L.; ABÊ, S.H. Transformações da indústria moveleira de Votuporanga. Votuporanga: [s/n], [s/d].

RODRIGUES, A.M. Moradia nas cidades brasileiras. 5. ed. São Paulo: Contexto, 1994.

RODRIGUES, F. Por onde vão as "Brisas Suaves do Sertão Paulista"?: População e estruturação urbana na constituição da cidade (im)possível, Votuporanga, um estudo de caso. Dissertação (Mestrado) - IFCH/Unicamp, Campinas, 2005.

Estudos de caracterização socioeconômico-demográfica. Subsídios para o Plano Diretor do Campus Norte da Unifev. Votuporanga: Unifev, 2004.

SEMPLA. Plano Diretor Municipal. Votuporanga: 1995.

SUZIGAN, W. et al. Aglomerados industriais em São Paulo. Campinas, Unicamp, [s/d]. Disponível em:

<http://www.unicamp.br>. Acesso em: 10 mar. 2004.

VILLAÇA, F. Espaço intra-urbano no Brasil. 2. ed. São Paulo: Studio Nobel, 2001.

Fabíola Rodrigues: Mestre em Demografia pela IFCH/NEPO/Unicamp (fabiola_rodrigue@yahoo.com.br).

Artigo recebido em 25 de abril de 2005 .

Aprovado em 5 de setembro de 2005. 